\title{
Role of LM23 in cell proliferation and apoptosis and its expression during the testis development
}

\author{
Qing Liu ${ }^{1 *}$, Ya-Juan Song ${ }^{1,2 *}$, Li-Jun Meng ${ }^{3}$, Fen $\mathrm{Hu}^{1}$, Li-Xia Gou ${ }^{1}$, Chang-Hong Jia ${ }^{1}$, Hong-Mei Tang ${ }^{1}$, \\ Wei-Jie Wang ${ }^{1}$, Mi Li ${ }^{1}$, Xiu-Jun Zhang ${ }^{1}$ and Meng-Chun Jia ${ }^{4}$
}

\begin{abstract}
LM23, a gene expressed specifically in the testis in a stage-specific manner, has a diverse range of functions that are important in both the life and death of spermatogenic cells. The aim of this study was to further investigate the expression of LM23 in the developing rat testis and the biological function of LM23 in proliferation and antiapoptosis in vitro. Semiquantitative reverse transcription (RT)-PCR and real-time PCR were used to examine the expression of LM23 in testis at different developmental stages. The results suggested that LM23 mRNA levels in the testis increased progressively after birth. The role of LM23 in proliferation was analyzed with cell counting kit-8 (CCK8), colony-forming efficiency (CFE) and flow cytometry assays. The results indicated that ectopic expression of LM23 in 293T cells significantly promoted cell proliferation by increasing cell numbers in S phase. Several methods were used, including CCK8, annexin V and propidium iodide staining and western blotting, to determine the role of LM23 in apoptosis. The results showed that $\mathrm{LM} 23$ played a protective role in $\mathrm{H}_{2} \mathrm{O}_{2}$-induced apoptosis of 293T cells, mediated at least in part through the Akt/PI3K signal pathway. Taken together, these results provide new insights into the role of LM23 in the development of the testes and
\end{abstract} spermatogenesis.

Asian Journal of Andrology (2013) 15, 539-544; doi:10.1038/aja.2013.43; published online 20 May 2013

Keywords: apoptosis; LM23; proliferation; rat testis

\section{INTRODUCTION}

The mammalian testis is a complex organ that serves two important functions: synthesis of steroids and production of spermatozoa. Spermatogenesis, or the differentiation of male germ cells to produce mature spermatozoa, is controlled by gonadotrophins and numerous locally synthesized factors. ${ }^{1}$ Spermatogenesis is divided into three distinct stages: the mitotic proliferation of spermatogonia, meiotic division of spermatocytes and spermiogenesis of haploid spermatids. This process of spermatogenesis involves transcriptional, translational and posttranslational regulation. Many spermatogenesis-related genes, which are specific to different phases of germ cell development, have been found in the past few years, and some, such as $L M 23$, have been proven to play important roles in spermatogenesis. ${ }^{2}$ LM23 (GenBank accession no. AF492385) cDNA consists of 1896 base pairs (bp) with a complete open reading frame of $936 \mathrm{bp}$, and encodes a putative protein including 312 amino acids. It has been shown that the LM23 gene is expressed specifically in the testis in a stage-specific manner, and may be involved in rat spermatogenesis, as previous reports from our laboratory have suggested. ${ }^{3}$

Cell proliferation, differentiation, senescence and apoptosis are cell cycle-dependent, and the basic regulatory mechanisms in cell cycle progression rely on a multicomponent system. At different phases, progression through the cell cycle is regulated by sequential activation and subsequent inactivation of a series of cyclin-dependent kinases, whose activity depends on interactions with cyclins and cyclindependent kinase inhibitors. ${ }^{4-6}$ Apoptosis is a type of programmed cell death characterized by the morphological changes of nuclear condensation and cell shrinkage. ${ }^{7,8}$ The process of apoptosis is regulated by several proteins, including members of the Bax, p53, Bcl-2 and caspase 3 protein families. ${ }^{9}$ A recent report has provided persuasive evidence that the knockdown of LM23, by lentivirus-mediated RNA interference, may result in downregulation of Cyclin A1, Cdk2, and CyclinB1, S and G2 phase delay, and eventually lead to apoptosis. ${ }^{10}$ This report also revealed that LM23 expression in the testis is crucial for meiosis during spermatogenesis in Rattus norvegicus. ${ }^{10}$ Further research in our laboratory has suggested that LM23 belongs to the Speedy/Ringo family and can regulate the G1/S and G2/M transitions of the cell cycle during spermatogenesis. ${ }^{2}$ However, the expression of LM23 in the developing rat testis has not been fully investigated, and a direct role for LM23 in cell proliferation and apoptosis or other LM23associated functions is yet to be established.

Additional, the testes of 35-day-old rat after LM23 knockdown by lentivirus-mediated RNA interference showed that the germ cells arrested at the spermatocyte stage, and apoptosis of pathytene spermatocytes was increased. ${ }^{10}$ The expression of some genes related to the cell cycle and apoptosis was markedly changed after LM23 knockdown, as

${ }^{1}$ College of Life Sciences, Hebei United University, Tangshan 063000, China; ${ }^{2}$ Department of Clinical Laboratory, Handan Central Hospital, Handan 056002, China; ${ }^{3}$ Department of Environment \& Chemical Engineering, Tangshan College, Tangshan 063000, China and ${ }^{4}$ Department of Reproductive Endocrinology, National Research Institute for Family Planning, Beijing 100081, China

* These authors contributed equally to this work.

Correspondence: Dr XJ Zhang (zhangxiujun66@163.com) and Dr MC Jia (mengchunjia@163.com)

Received: 10 January 2013; Revised: 20 February 2013; Accepted: 17 March 2013; Published online: 20 May 2013 
shown by the microarray analysis. The downregulation of LM23 might block the G1/S and G2/M transitions of the spermatogenic cell. ${ }^{2}$ Since no suitable male germ cell lines are available now, we have to use somatic cell line to investigate the function of LM23 in apoptosis, cell proliferation and cell cycle.

The objective of the present study was to address both these issues. The in vivo expression of LM23 in the developing rat testis was examined using semiquantitative reverse transcription (RT)-PCR and real-time PCR. To investigate the role of LM23 in apoptosis, cell proliferation and cell cycle progression in vitro, 293T cells transfected with LM23 expression plasmids were used in cell counting kit-8 (CCK8) and flow cytometry assays. Western blotting, annexin V and propidium iodide staining and proliferation assays were used to investigate the effect of LM23 overexpression in $\mathrm{H}_{2} \mathrm{O}_{2}$-induced apoptosis and its possible mechanisms of action in $293 \mathrm{~T}$ cells. The results provide new insights into the role of LM23 in the development of the testes.

\section{MATERIALS AND METHODS}

\section{Animals and tissue preparation}

Male Sprague-Dawley rats were purchased from Peking University Laboratory Animal Center. Rats were obtained at 0, 5, 14, 21, 30 and 65 days after birth. The testes were obtained from three rats at each age.

\section{RT-PCR and real-time PCR}

Total RNA was extracted from the testes according to the manufacturer's protocol for Trizol Reagent (Invitrogen, Carlsbad, CA, USA). For each sample, cDNA synthesis was carried out using $0.25 \mu \mathrm{g}$ of total RNA and PrimeScript RT Master Mix Perfect Real-Time (TaKaRa, Tokyo, Japan). Specific transcripts of LM23 were amplified by quantitative PCR using the following primers: LM23, 5'-AGATACGTGAGACTGGGACTGT $3^{\prime}$ (forward) and 5'-CGTGCTTTAGTTGAGCCTTG-3' (reverse); GAPDH, 5'-AAGAAGGTGGTGAAGCAGGC-3' (forward) and 5' -TCCACCACCCTGTTGCTGTA-3' (reverse). GAPDH was used as an internal control. The real-time PCR was conducted using SYBR Green PCR Master Mix Reagent (SYBR Premix Ex Taq kit; TaKaRa) and an ABI Stepone Sequence Detection System (PE Applied-Biosystems, Streetsville, Canada). The level of mRNA was expressed as the threshold cycle values of the target gene and reference gene, GAPDH, which is constitutively expressed. Comparison of threshold cycle values was used to determine the relative mRNA levels, expressed as the fold change of the target gene relative to the reference gene.

\section{Plasmid construction}

The generation of vector (pGEM-T-LM23) has been previously described. ${ }^{2}$ Full-length LM23 fragment was obtained by double enzyme digestion from pGEM-T-LM23 and cloned into the pcDNA3.1/ myc-His (-) B vector ( $\mathrm{pcDB}$; Invitrogen), using the restriction enzymes EcoRI and BamHI.

\section{Cell culture and transient transfection}

HEK 293T (human embryonic kidney cell line, a kind gift from T. Matsuda, Japan) cells were maintained in Dulbecco's modified Eagle's medium (HyClone, Logan, UT, USA) supplemented with 10\% fetal bovine serum (Gibco, Grand Island, NY, USA) and were incubated in a $5 \% \mathrm{CO}_{2}$ incubator at $37^{\circ} \mathrm{C}$. Plasmids were transfected into $293 \mathrm{~T}$ cells using VigoFect (Vigorous Biotechnology, Beijing, China), according to the manufacturer's instructions.

\section{CCK8 assay}

293T cells transfected with pcDB vector control or pcDB-LM23 were plated in a 96-well plate at a concentration of 2000 cells per well. At 0 , $1,2,3,4$ and 5 days after transfection, the cell proliferation assay was performed by the addition of $10 \mu \mathrm{l} \mathrm{CCK8}$ solution (Dojindo, Tokyo, Japan) to each well, followed by incubation at $37{ }^{\circ} \mathrm{C}$ for $2 \mathrm{~h}$. Absorbance was measured at a wavelength of $450 \mathrm{~nm}$ using a microplate reader (Synergy 2 Multi-Mode Microplate Reader; BioTek, Winooski, VT, USA).

\section{Flow cytometry with propidium iodide staining}

$293 \mathrm{~T}$ cells were synchronized with $12 \mathrm{~h}$ of serum starvation, and then transfected with $2.5 \mu \mathrm{g}$ of pcDB vector control or pcDB-LM23. Cells were trypsinized at $24 \mathrm{~h}$ after transfection, washed twice with phosphate-buffered saline (PBS), and fixed with ice-cold $70 \%$ ethanol. The fixed cells were pelleted, washed and resuspended in PBS. Samples were treated with $1 \mu \mathrm{l}$ of a $10 \mathrm{mg} \mathrm{ml}^{-1}$ stock of DNase-free RNase A (Promega, Madison, WI, USA) and incubated at $37{ }^{\circ} \mathrm{C}$ for $30 \mathrm{~min}$. They were then treated with $50 \mu \mathrm{l}$ of $300 \mathrm{mg} \mathrm{ml}^{-1}$ propidium iodide (Boehringer, Indianapolis, IN, USA) containing Triton X-100 and incubated in the dark within $30 \mathrm{~min}$. Data were collected on a flow cytometer (FACSCalibur; BD Biosciences, Franklin Lakes, NJ, USA).

\section{Colony-forming efficiency (CFE)}

$293 \mathrm{~T}$ cells transfected with pcDB or pcDB-LM23 were plated in a 6-well plate at a concentration of 500 cells per well and incubated at $37^{\circ} \mathrm{C}$ for 14 days. Colonies were then stained with crystal violet solution, and the number of colonies was counted. The CFE of each group was expressed as a percentage of the total number of colonies in pcDBtransfected controls.

\section{Western blotting}

293T cells were transfected with pcDB or pcDB-LM23. After $24 \mathrm{~h}$, cells were washed twice with ice-cold PBS and lysed in cell lysis buffer $(1 \times$ PBS, $1 \%$ NP40, $0.5 \%$ sodium deoxycholate, $0.1 \%$ sodium dodycl sulfate, with freshly added proteinase inhibitor cocktail) for $30 \mathrm{~min}$ at $4{ }^{\circ} \mathrm{C}$. Cell lysates were clarified by centrifugation at $4{ }^{\circ} \mathrm{C}$ at $16000 \mathrm{~g}$ for $15 \mathrm{~min}$. The total protein concentration was determined using the BCA protein assay kit (Vigorous Biotechnology). Equal amounts of protein were separated by $12.5 \%$ sodium dodycl sulfate-polyacrylamide gel electrophoresis and transferred onto polyvinylidene difluoride membrane. Membranes were blocked in Tris-buffered saline containing $0.1 \%$ Tween-20 and 5\% non-fat milk for $2 \mathrm{~h}$, and incubated overnight at $4{ }^{\circ} \mathrm{C}$ with the appropriate primary antibody. After washing in Tris-buffered saline containing $0.1 \%$ Tween-20 buffer, membranes were incubated for $1 \mathrm{~h}$ in the dark with the appropriate horseradish peroxidase-conjugated secondary antibodies. Antibody reactivity was visualized with an enhanced chemiluminescent substrate (Invitrogen). Antibodies specific for the following proteins were used: Bcl-2-associated protein (Bax), p53, caspase 3 (Santa Cruz Biotechnology, Santa Cruz, CA, USA), Bcl-2 (Cell Signaling Technology, Beverly, MA, USA) and actin (Sigma, St Louis, MO, USA). Dilution ( $1: 1000)$ was used to detect actin, and all the other antibodies were used at the 1:500 dilution.

\section{Transient expression dual-luciferase reporter assay}

293 T cells were seeded into a 96-well plate at $1 \times 10^{4}$ cells per plate. After $24 \mathrm{~h}$, the cells in each well were cotransfected with $80 \mathrm{ng}$ of the pcDB-LM23 or pcDB vector control plasmids, $40 \mathrm{ng}$ of the pNF- $\kappa \mathrm{B}-\mathrm{Luc}$ plasmids containing the firefly luciferase reporter gene (PathDetect; Stratagene, La Jolla, CA, USA) and 4 ng of the pRL-TK 
plasmid as the internal control containing the Renilla luciferase gene (Promega). Each transfection experiment was performed in triplicate wells. At $24 \mathrm{~h}$ after transfection, the cells were lysed in standard lysis buffer (Promega). The cell lysates were assayed for both firefly and Renilla luciferase activities with the dual-luciferase reporter assay system (Promega), according to the manufacturer's instructions, using a GENios Pro reader (Tecan, Mannedorf, Switzerland). Luciferase activity was normalized to the Renilla luciferase activity. All experiments were performed in duplicate.

Flow cytometry analysis with annexin $\mathrm{V}$ and propidium iodide staining

293 T cells were transfected with 80 ng of the pcDB-LM23 or pcDB plasmids. At $24 \mathrm{~h}$ after transfection, 293T cells were stained according to the manufacturer's instructions of Annexin V-FITC/PI kit (PharMingen). Flow cytometry was conducted on an FACS calibur system and the results were analyzed by CellQuest software (Becton Dickinson, Mountain View, CA, USA).

\section{RESULTS}

\section{Expression of LM23 mRNA in testis development}

LM23 is known to be specifically expressed in testis, ${ }^{3}$ but its expression in the developing rat testis has not been established. In order to investigate the expression of LM23 in testis development and spermatogenesis, the semiquantitative RT-PCR and real-time PCR were performed to examine the expression of LM23 at different periods of testicular development. The results showed that the LM23 mRNA level in the testis was low at day 0 after birth, and then increased progressively during postnatal testis development (Figure 1a and $\mathbf{1 b}$ ). The expression of LM23 mRNA reached a peak level at day 30 after birth, and then decreased at day 65 after birth (Figure 1b). These data indicate that LM23 expression is stage-specific during testis development.
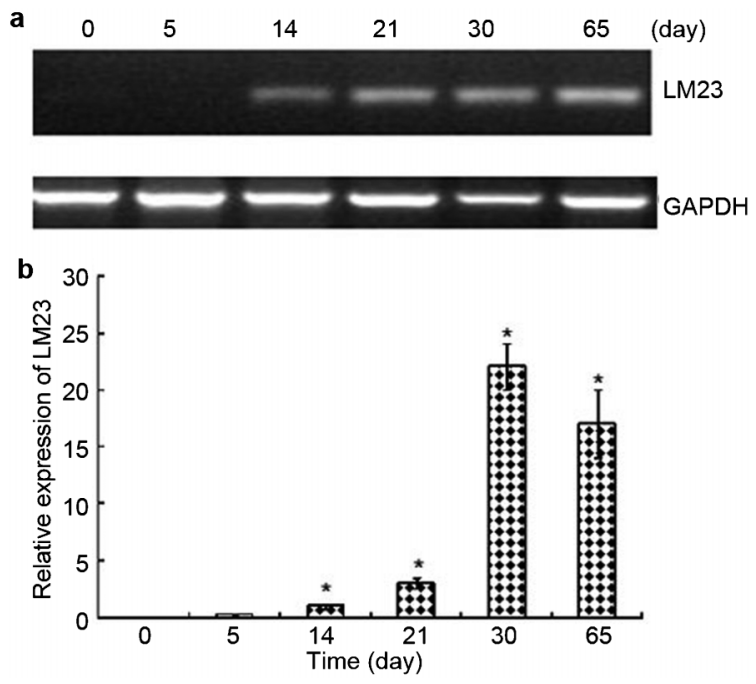

Figure 1 Quantitative analysis of LM23 expression during postnatal development in the rat testis by semiquantitative RT-PCR (a) and real-time PCR analysis (b). The RNA prepared from testes illustrates the changing levels of LM23 mRNA in the testis at days $0,5,14,21,30$ and 65 postpartum (dpp). The data are representative images from groups of rats ( $n=3$ per group). All values are expressed as mean \pm s.d. $* P<0.05$ in an unpaired $t$ test when compared with vector alone. $\mathrm{RT}$, reverse transcription; s.d., standard deviation.

\section{Overexpression of LM23 enhanced cell proliferation}

We have previously reported that LM23 may regulate cell cycle progression during spermatogenesis. ${ }^{2}$ In the present study, the effect of LM23 on cell cycle progression of 293 T cells was investigated using a range of cell proliferation assays. As shown in Figure 2a, cell numbers in LM23-overexpressing cells increased significantly after 2 days, compared to cells transfected with the empty vector. Figure $2 \mathbf{b}$ shows that, in LM23-overexpressing cells, CFE was also increased compared to the control cells. The CFE ratio was 3.08-fold higher than in controls. These results indicated a promoting effect of LM23 on the proliferation of 293 T cells. Furthermore, flow cytometric measurements of LM23overexpressing 293T cells after propidium iodide staining confirmed an increase in the number of cells in S phase. Twenty-four hours after transfection of $293 \mathrm{~T}$ cells with LM23 expression plasmid or empty vector control, the percentage of cells in S phase was $53.66 \% \pm 0.7 \%$ in the LM23-overexpressing sample, and $42.37 \% \pm 0.8 \%$ in controls (Figure 2c). The results indicated that LM23 reduced the proportion of cells in G0/G1 phase, but increased the number of $S$ phase cells. Taken together, these data suggest that LM23 significantly promotes cell cycle progression into S phase in $293 \mathrm{~T}$ cells.

\section{Overexpression of LM23 activated nuclear factor (NF)- $\mathrm{KB}$}

In order to investigate the function of LM23, a dual-luciferase reporter assay system was used to examine LM23 expression in mammalian cells. It was found that overexpression of LM23 activated the NF- $\kappa \mathrm{B}$ reporter gene in $293 \mathrm{~T}$ cells when compared to control 293T cells transfected with empty vector controls (Figure 2d).
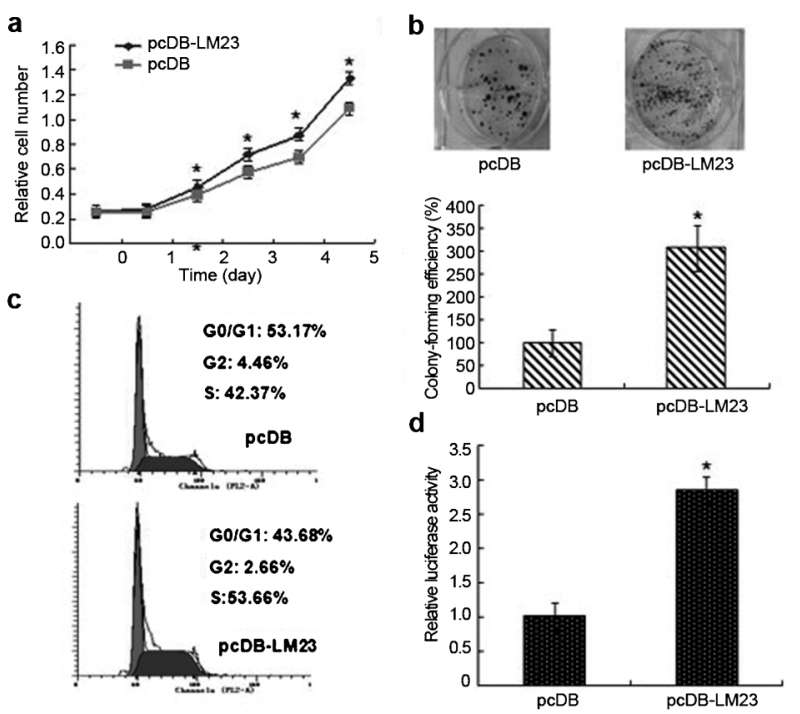

Figure 2 Overexpression of LM23 promoting cell proliferation and inducing NF- $\kappa B$ activation. (a) $293 \mathrm{~T}$ cells transfected with pcDB or pcDB-LM23 were assayed with a CCK8. Cells were collected every $24 \mathrm{~h}$, and the absorbance was measured at $450 \mathrm{~nm}$. (b) 293T cells were transfected with pcDB or pcDB-LM23, and colony-forming efficiency was analyzed for 14 days after transfection. The colony-forming efficiency was expressed as a percentage of the total number of colonies in the pcDB controls. (c) 293T cells transfected with pcDB or pcDBLM23 were harvested, fixed and stained with $\mathrm{PI}$, and then analyzed by flow cytometry. $* P<0.05$ in unpaired $t$ test when compared with vector alone. (d) 293T cells were transfected with either the empty pcDB vector control or pcDB-LM23 along with pNF-кB-luc and pRL-TK. A dual-luciferase reporter gene assay was performed using the lysates from transfected cells. $* P<0.05$ in unpaired $t$ test when compared with empty vector control. CCK8, cell counting

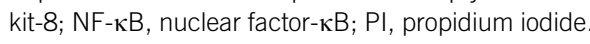


LM23 protects against $\mathrm{H}_{2} \mathrm{O}_{2}$-induced apoptosis

Exogenous $\mathrm{H}_{2} \mathrm{O}_{2}$ was used to induce free radical-mediated apoptosis in $293 \mathrm{~T}$ cells. Cell apoptosis was quantified by CCK8 assays. As shown in Figure 3a, $\mathrm{H}_{2} \mathrm{O}_{2}$ at concentrations between 100 and $500 \mu \mathrm{mol} \mathrm{l}^{-1}$ induced apoptosis of $293 \mathrm{~T}$ cells in a dose-dependent manner. To evaluate the effects of LM23 on $\mathrm{H}_{2} \mathrm{O}_{2}$-induced apoptosis, 293T cells were transfected with pcDB-LM 23 or pcDB vector control plasmids for $24 \mathrm{~h}$, and then treated with various concentrations of $\mathrm{H}_{2} \mathrm{O}_{2}$ for $12 \mathrm{~h}$. The effects of $\mathrm{H}_{2} \mathrm{O}_{2}$-induced apoptosis were reduced in the LM23overexpressing cells (Figure 3b). A concentration of $200 \mu \mathrm{mol} 1^{-1}$ $\mathrm{H}_{2} \mathrm{O}_{2}$ was chosen for subsequent studies, because this dose induced moderate apoptosis. Annexin $\mathrm{V}$ and propidium iodide staining of $293 \mathrm{~T}$ cells confirmed the antiapoptotic effects of LM23. The treatment with $\mathrm{H}_{2} \mathrm{O}_{2}$ caused a significant increase in late apoptotic and early apoptotic $293 \mathrm{~T}$ cells in comparison to the untreated controls, whereas LM23 overexpression in 293T cells reduced the $\mathrm{H}_{2} \mathrm{O}_{2}$-induced apoptosis (Figure 3c). These observations suggest that LM23 plays a protective role against $\mathrm{H}_{2} \mathrm{O}_{2}$-induced apoptosis in $293 \mathrm{~T}$ cells.

To understand the molecular changes involved, western blots was performed to examine the effects of LM23 and $\mathrm{H}_{2} \mathrm{O}_{2}$ on the expression of the apoptotic proteins $\mathrm{Bax}, \mathrm{p} 53, \mathrm{Bcl}-2$ and caspase 3 . 293T cells were transfected with pcDB-LM23 or pcDB vector control plasmids for $24 \mathrm{~h}$, followed by the addition of $200 \mu \mathrm{mol} \mathrm{l} \mathrm{l}^{-1} \mathrm{H}_{2} \mathrm{O}_{2}$ for $12 \mathrm{~h}$. Overexpression of LM23 in 293T cells decreased the expression of Bax, p53 and caspase 3, in the absence of $\mathrm{H}_{2} \mathrm{O}_{2}$. Similarly, the levels of $\mathrm{H}_{2} \mathrm{O}_{2}$-induced $\mathrm{Bax}, \mathrm{p} 53$ and caspase 3 expression were significantly reduced by LM 23 overexpression. No differences in Bcl-2 expression

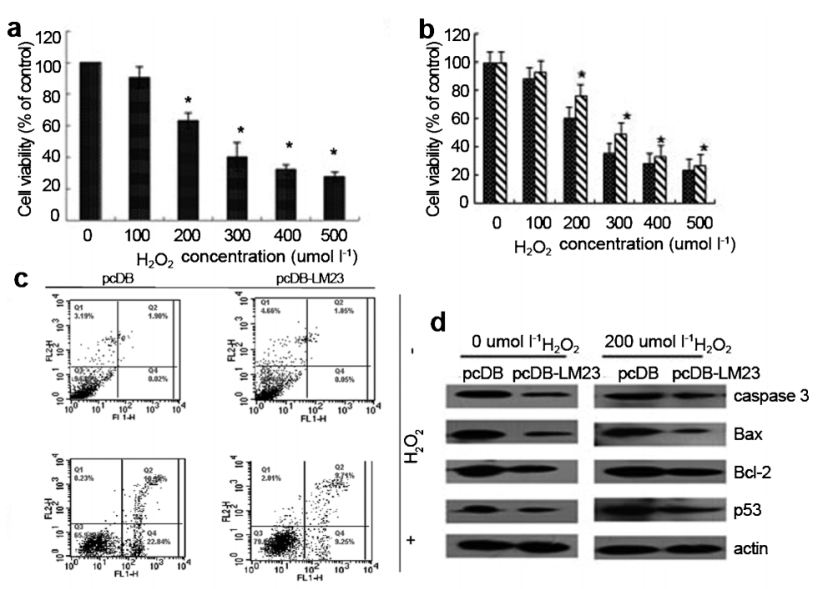

Figure 3 LM23 decreasing $\mathrm{H}_{2} \mathrm{O}_{2}$-induced cell apoptosis. (a) 293T cells were treated with 0, 100, 200,300, 400 or $500 \mu$ mol I-1 $\mathrm{H}_{2} \mathrm{O}_{2}$ and harvested after $12 \mathrm{~h}$. Cell viability was determined by CCK8 assay. The mean and s.d. values were calculated from six replicates. (b) 293T cells were transfected with pcDB or pcDB-LM23. After $24 \mathrm{~h}$, the cells were treated with $0-500 \mu \mathrm{mol} \mathrm{I}-1 \mathrm{H}_{2} \mathrm{O}_{2}$ as described above, and cell viability was measured by CCK8 assay. (c) 293 T cells transfected with pcDB or pcDB-LM23 for $24 \mathrm{~h}$, and untransfected control 293T cells, were cultured with or without $200 \mu \mathrm{mol} \mathrm{I}{ }^{-1} \mathrm{H}_{2} \mathrm{O}_{2}$ for a further $12 \mathrm{~h}$. 293T cells were fixed and stained with annexin V/PI, and then analyzed by flow cytometry. FL1-H and FL2-H correspond to annexin V and PI staining respectively. Quadrants Q1, Q2, Q3 and Q4 correspond to necrotic cells, late apoptotic cells, viable cells and early apoptotic cells, respectively. $* P<0.05$ in unpaired $t$ test when compared with vector alone. (d) LM23 downregulates Bax, p53 and caspase 3 expression while protecting against $\mathrm{H}_{2} \mathrm{O}_{2}$-induced apoptosis. 293T cells were transfected with pcDB (control) or pcDB-LM23 vector. After $24 \mathrm{~h}$, the cells were treated with $200 \mu \mathrm{mol} \mathrm{I}{ }^{-1} \mathrm{H}_{2} \mathrm{O}_{2}$ for $12 \mathrm{~h}$. The levels of Bax, p53, Bcl-2 and caspase 3 proteins were measured by western blotting. Actin was used as control. CCK8, cell counting kit-8; PI, propidium iodide; s.d., standard deviation.

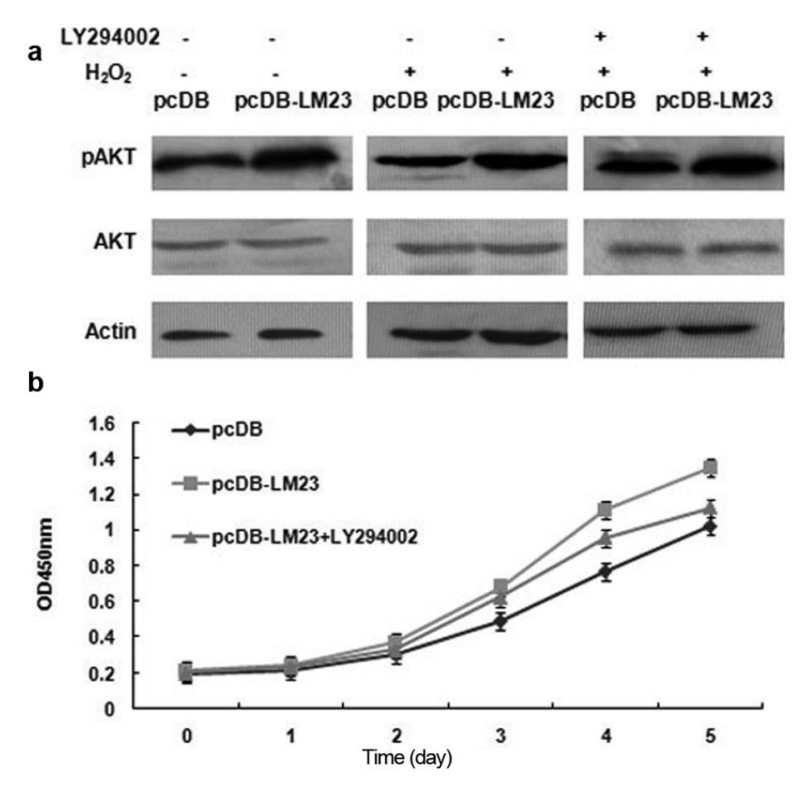

Figure 4 Effect of LM23 on cell survival is mediated by activation of Akt/PI3K signaling. (a) 293T cells transfected with pcDB or pcDB-LM23 vectors for $24 \mathrm{~h}$ were cultured with or without, $200 \mu \mathrm{mol} \mathrm{I}^{-1} \mathrm{H}_{2} \mathrm{O}_{2}$ and $5 \mu \mathrm{mol} \mathrm{I}^{-1} \mathrm{LY} 294002$. The levels of AktT, pAKT and actin were measured by western blotting. Actin was used to normalize the AktT and pAKT levels. (b) CCK8 assays were used to verify that LY294002 at least partially blocked the LM23-induced increase in cell viability of 293T cells. CCK8, cell counting kit-8.

were detected (Figure 3d). These data suggest that LM23 prevents $\mathrm{H}_{2} \mathrm{O}_{2}$-induced apoptosis in $293 \mathrm{~T}$ cells via a decrease in the expression of Bax, p53 and caspase 3.

\section{Effects of LM23 on Akt/PI3K signaling}

Akt/PI3K signaling plays a crucial role in a variety of cellular events including apoptosis and proliferation. ${ }^{11-13}$ In the present study, western blotting was used to investigate whether the Akt/PI3K signaling pathways contributed to the antiapoptotic function of LM23. Figure 4a shows that overexpression of LM23 in 293T cells significantly activated phosphorylation of Akt, in the presence or absence of $\mathrm{H}_{2} \mathrm{O}_{2}$, in comparison with control cells transfected with empty vector. Given that LM23 overexpression resulted in a strong activation of the Akt signal pathway (Figure 4a), 293T cells were transfected with LM23 expression plasmid or empty vector control for $24 \mathrm{~h}$ followed by treatment with $5 \mu \mathrm{mol}{ }^{-1} \mathrm{PI} 3 \mathrm{~K}$ inhibitor LY294002 for $3 \mathrm{~h}$, and then treated with $200 \mu \mathrm{moll}^{-1} \mathrm{H}_{2} \mathrm{O}_{2}$ for $12 \mathrm{~h}$. Western blotting showed that blockade of the Akt/PI3K signaling pathway by LY294002 dramatically weakened LM23-induced expression of pAkt (Figure 4a). Cell viability was also determined by CCK8 assay. The results showed that LY294002 at least partially blocked the LM23-induced increase in cell viability (Figure $\mathbf{4 b}$ ). These data therefore imply that the protective effect of LM23 in $\mathrm{H}_{2} \mathrm{O}_{2}$-induced apoptosis is mediated at least in part through the Akt/PI3K signaling pathway.

\section{DISCUSSION}

In higher eukaryotes, spermatogenesis is a very complex process of differentiation. During this process, primordial germ cells firstly form gonocytes, or prespermatogonia. After birth, gonocytes reenter the cell cycle and then become spermatogonia. Some of these spermatogonia form the self-renewing stem cell pool, while others differentiate immediately to spermatocytes. Spermatocytes undergo meiosis to further 
differentiate into haploid spermatids, and are finally transformed into mature sperm. Spermatogenesis is influenced by many genes and cellular factors in a time-dependent and cycle-specific manner, resulting in coordinated and orderly development. We previously demonstrated that LM23 was one of the genes involved in spermatogenesis. ${ }^{3}$

Previously we detected expression of LM 23 mRNA by SYBR Greenbased quantitative PCR in type A spermatogonia, pathytene spermatocytes and round spermatids, respectively. The results suggested that the expression level of LM23 was highest in spermatocytes, moderate in round spermatids and very low in spermatogonia. ${ }^{3}$ We also examined cell-specific expression in rat testis using a polyclonal rabbit anti-LM23 antibody by immunohistochemical analysis. The positive immunological activity was mainly located in the nucleus of spermatocytes and round spermatids, but few in elongating spermatids and mature sperm. ${ }^{2}$

In this study, the RNA prepared from testes illustrated changing levels of LM23 mRNA in the testis at $0,5,14,21,30$ and 65 days postpartum (dpp) (Figure 1a). None or very low expression of LM23 was detected at 0 and $5 \mathrm{dpp}$, since there are only primitive type A spermatogonia and Sertoli cells in the testis. In 14 dpp (prepuberty), the expression of LM23 was started, while the meiotic prophase is initiated and the germ cells reach the early and late pachytene stages in testis. The expression of LM23 reached the peak level at $30 \mathrm{dpp}$ (prepuberty), then decreased at day $65 \mathrm{dpp}$ (postpuberty). ${ }^{14,15}$ In the testis of $65 \mathrm{dpp}$ rat, ther are a large amount of elongating spermatids and mature sperms which have no or very low expression of LM23, so expression of LM23 is decreased. The changes of LM23 are coincided with the development of germ cells in the rat testis.

$\mathrm{NF}-\kappa \mathrm{B}$ is a generic term for a dimeric transcription factor formed by the heterodimerization or homodimerization of members of the Rel/

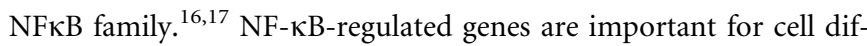
ferentiation, embryonic development, the immune response and inflammation, ${ }^{18-20}$ as well as the development, progression and drug resistance of cancer cells. ${ }^{17,21}$ Our study demonstrated that LM23 activated the NF- $\kappa \mathrm{B}$ pathway, suggesting that it may be an important regulator of a variety of cell functions.

In mammals, there are at least five different Speedy/Ringo homologs and all of them can bind to and activate cyclin-dependent kinases, which suggests that Speedy/Ringo proteins may play versatile roles in cell cycle control. ${ }^{22-24}$ Speedy A (Spdya), a human Speedy homolog, is a novel cell cycle protein capable of promoting cell proliferation. ${ }^{25}$ LM23 is a $R$. norvegicus homolog of Speedy A. ${ }^{2}$ Our results showed that LM23 promoted $293 \mathrm{~T}$ cell cycle progression by increasing cell numbers in $S$ phase of the mitotic cell cycle, suggesting that LM23 may be an important regulator of cell cycle progression. Liu et al. ${ }^{10}$ have shown that the knockdown of LM23 may result in downregulation of Cyclin A1, Cdk2 and CyclinB1. However, they noted that the mechanism through which LM23 promoted HEK 293 cell proliferation required further elucidation.

Speedy A, also known as SPY1, not only promotes cell proliferation under normal circumstances, but also promotes cell survival under conditions of genotoxic stress. ${ }^{25,26}$ Barnes et al. ${ }^{26}$ showed that Spy1 could override the DNA damage response, by inhibiting DNA damage-induced apoptosis. As LM23 is homologous to Spy1, it may also play a key role in regulating both cell growth and apoptosis. Spy1 expression in mammalian cells enhances survival under conditions of genotoxic damage, including treatment with CPT, cisplatin and $\mathrm{HU}^{26}$ These results are consistent with our findings that LM23 markedly promotes the survival of $293 \mathrm{~T}$ cell after $\mathrm{H}_{2} \mathrm{O}_{2}$ treatment. Apoptosis is a process of programmed cell death, and involves a series of morphological changes, including cell detachment, cell shrinkage, mitochondria leakage, chromatin condensation and DNA fragmentation. $^{27,28}$ Our results found that LM23 decreased the apoptosis of 293T cells induced by $\mathrm{H}_{2} \mathrm{O}_{2}$. These data suggest that LM23 has a protective role in $\mathrm{H}_{2} \mathrm{O}_{2}$-induced apoptosis in $293 \mathrm{~T}$ cells.

The process of apoptosis is regulated by several proteins, including members of the Bax, p53, Bcl-2 and caspase 3 protein families. ${ }^{9}$ Caspases, which are cysteine aspartic proteases, play essential roles at various stages of the apoptotic process. ${ }^{29}$ Caspase 3 is a key mediator of apoptosis and a common downstream effector of multiple apoptotic signaling pathways. ${ }^{30}$ These results are consistent with our findings that the protective effect of LM23 in $\mathrm{H}_{2} \mathrm{O}_{2}$-induced apoptosis was associated with an obvious decrease in the expression of Bax, p53 and caspase 3 in $293 \mathrm{~T}$ cells. Akt, a serine/threonine kinase, plays a crucial role in a variety of cellular events including apoptosis and proliferation. ${ }^{11-13,27}$ Akt activation is a critical component of the PI3K downstream cascade during growth factor stimulation. ${ }^{31}$ The results presented in this study also showed that prevention of $\mathrm{H}_{2} \mathrm{O}_{2}$ induced apoptosis by LM23 was mediated at least in part through the Akt/PI3K signal pathway.

In conclusion, LM23 promoted 293T cell cycle progression and played a protective role during $\mathrm{H}_{2} \mathrm{O}_{2}$-induced apoptosis of $293 \mathrm{~T}$ cells. We therefore propose that LM23 might act as a potential regulatory factor at the crossroads between proliferation and apoptosis in cell. However, the in vivo mechanisms of action of LM23 are likely to be far more complex. Further investigation in vivo is required to elucidate the exact role of LM23 in postnatal testis development and spermatogenesis.

\section{AUTHOR CONTRIBUTIONS}

QL, YJS and LJM conceived and designed the study. FH, LXG, CHJ, HMT and WJW collected the data. QL, YJS and ML performed the statistical analyses. QL, XJZ and MCJ wrote the manuscript with input from all of the coauthors. All of the authors revised the manuscript and approved the final version.

\section{COMPETING FINANCIAL INTERESTS}

All authors declare that there are no competing financial interests.

\section{ACKNOWLEDGMENTS}

This work was supported by the National Natural Science Foundation of China (Nos. 81170616, 81072093 and 30671092) and the Natural Science Foundation of Hebei Province (Nos. C2009001260 and C2013209024).

1 Saez JM. Leydig cells: endocrine, paracrine, and autocrine regulation. Endocr Rev 1994; 15: 574-626.

2 Cheng YM, Liu ML, Jia MC. LM23 is a novel member of the Speedy/Ringo family at the crossroads of life and death of spermatogenic cell. Asian J Androl2011; 13: 446-52.

3 Liu ML, Pei KY, Shi XQ, Liu DY, Jia MC. Identification and characterization of a nove spermatogenesis related gene LM23 in rat testis. Biochem Biophys Res Commun 2007; 356: 576-81.

4 Draetta G. Cell cycle control in eukaryotes: molecular mechanisms of cdc2 activation. Trends Biochem Sci 1990; 15: 378-83.

5 Sherr CJ. G1 phase progression: cycling on cue. Cell 1994; 79: 551-5.

6 Caldon CE, Daly RJ, Sutherland RL, Musgrove EA. Cell cycle control in breast cancer cells. J Cell Biochem 2006; 97: 261-74.

7 Hale AJ, Smith CA, Sutherland LC, Stoneman VE, Longthorne V et al. Apoptosis: molecular regulation of cell death. Eur J Biochem 1996; 237: 884.

8 Vaux DL, Strasser A. The molecular biology of apoptosis. Proc Natl Acad Sci USA 1996; 93: 2239-44

9 Jung EM, Choi KC, Jeung EB. Expression of calbindin-D28k is inversely correlated with proapototic gene expression in hydrogen peroxide-induced cell death in endometrial cancer cells. Int J Oncol 2011; 38: 1059-66. 
neg

Functional analysis of LM23

Q Lu et al

544

10 Li ML, Chen YM, Ja MC. LM23 is essential for spermatogenesis in Rattus norvegicus. Front Biosci (Elite Ed) 2010; 2: 187-94.

11 Yang L, Dan HC, Sun M, Lu Q, Sun XM et al. Akt/protein kinase B signaling inhibitor-2, a selective small molecule inhibitor of Pkt signaling with antitumor activity in cancer cells overexpressing Alt. Cancer Res 2004; 64: 4394-9.

12 Brazil DP, Yang ZZ, Hemming BA. Advances in protein kinase B signalling: AKTion on multiple fronts. Trends Biochem Sci 2004; 29: 233-42.

$13 \mathrm{Kim}$ JH, Yang YI, Lee KT, Park HJ, Choli JH. Costunolide induces apoptosis in human endometriotic cells through inhibition of the prosurvival Akt and nuclear factor kappa B signaling pathway. Biol Pharm Bull 2011; 34: 580-5.

14 Huckins $C$, Clermont $Y$. Evolution of gonocyte in the rat testis during late embryonic and early postnatal life. Arch Anat Histol Embryol 1968; 51: 34154.

15 Huckins $C$. The spermatogonial stem cell population in adult rats. I. Their morphology, proliferation and maturation. Anat Rec 1971; 169: 533-57.

16 Karin M, Ben-Neriah Y. Phosphorylation meets ubiquitination: the control of NF[kappa]B activity. Ann Rev Immunol 2000; 18: 621-63.

17 Ikezoe T, Yang Y, Bandobashi K, Saito T, Takemoto S et al. Oridonin, a diterpenoid purified from Rabdosia rubescent, inhibits the proliferation of cells from lymphoid malignancies in association with blockade of the NF-kappa B signal pathways. Mol Cancer Then 2005; 4: 578-86.

18 Karin M. Nuclear factor-kappaB in cancer development and progression. Nature 2006; 441: 431-6.

19 Lu JL, Tan W, Ricono JM, Korchynskyi O, Zhang M et al. Nuclear cytokine-activated IKKalpha controls prostate cancer metastasis by repressing Maspin. Nature 2007; 446: 690-4.
20 Leo JL, Maeda S, Hsu LC, Yagita H, Karin M. Inhibition of NF-kappaB in cancer cells converts inflammation-induced tumor growth mediated by TNFalpha to TRAILmediated tumor regression. Cancer Cell 2004; 6: 297-305.

21 Karin M, Gao Y, Green FR, Li ZW. NF-kappaB in cancer: from innocent bystander to major culprit. Nat Rev Cancer 2002; 2: 301-10.

22 Dinarina A, Perez LH, Davila A, Schwab M, Hunt T et al. Characterization of a new family of cyclin-dependent kinase activators. Biochem J 2005; 386: 349-55.

23 Chen A, Xiong W, Ferrell JE Jr, Solomon MJ. Identification and comparative analysis of multiple mammalian Speedy/Ringo proteins. Cell Cycle 2005; 4: 155-65.

24 Ching $A$, Solomon MJ. Speedy/Ringo $C$ regulates $S$ and $G 2$ phase progression in human cells. Cell Cycle 2008; 7: 3037-47.

25 Porter LA, Dillinger RW, Tynan JA, Barnes EA, Kong M et al. Human Speedy: a novel cell cycle regulator that enhances proliferation through activation of Cdk2. J Cell Biol 2002; 157: 357-66.

26 Barnes EA, Porter LA, Lenormand JL, Dellinger RW, Donoghue DJ. Human Spy 1 promotes survival of mammalian cells following DNA damage. Cancer Res 2003; 63: 3701-7.

27 Kanazawa I. How do neurons die in neurodegenerative diseases? Trends Mol Med 2001; 7: 339-44.

28 Chen IH, Lin YC, Hang E, Huang HT, Chang WH et al. Collagen VI protects against neuronal apoptosis elicited by ultraviolet irradiation via an Akt/phosphatidylinositol 3kinase signaling pathway. Neuroscience 2011; 183: 178-88.

29 Wang $H$, Wang $P$, Sun $X$, Lu $Y$, Wang $X$ et al. Cloning and characterization of a novel caspase-10 isoform that activates NF-kappa B activity. Biochim Biophys Acta 2007; 1770: 1528-37.

30 Thornberry NA, Lazebnik Y. Caspases: enemies within. Science 1998; 281: 1312-6.

31 Downward J. Signal transduction. A target for PI(3) kinase. Nature 1995; 376: 553-4.

Asian Journal of Andrology 